\title{
Postsynaptic Density Protein-95 Regulates NMDA Channel Gating and Surface Expression
}

\author{
Ying Lin, V. Arvydas Skeberdis, Anna Francesconi, Michael V. L. Bennett, and R. Suzanne Zukin \\ Department of Neuroscience, Albert Einstein College of Medicine, Bronx, New York 10461-1975
}

\begin{abstract}
NMDA receptors (NMDARs) colocalize with postsynaptic density protein-95 (PSD-95), a multivalent synaptic scaffolding protein and core component of the postsynaptic density, at excitatory synapses. Although much is known about the identity and properties of scaffolding proteins, little is known about their actions on NMDAR function. Here we show that association of PSD-95 with NMDARs modulates channel gating and surface expression. PSD-95 increases the number of functional channels at the cell surface and channel opening rate of NMDARs, with little or no change in conductance, reversal potential, or mean open time. We show further that PSD-95 increases NMDAR surface expression by increasing the rate of channel insertion and decreasing the rate of channel internalization. The PDZ (PSD-95, discs large, zona occludens-1) binding motif at the distal end of the NR2 C-terminal tail is critical to the actions of PSD-95 on NMDAR function and surface expression. Given that activity bi-directionally modifies synaptic levels of PSD-95, our findings suggest a novel mechanism for activity-dependent regulation of NMDARs at central synapses.
\end{abstract}

Key words: PSD-95; SAP-90; zona occludens family of proteins; PDZ proteins; scaffolding proteins; excitatory synapses; NMDA receptors; channel gating; receptor trafficking

\section{Introduction}

NMDA receptors (NMDARs) are glutamate-gated ion channels that are localized to excitatory synapses throughout the brain. Activity-dependent $\mathrm{Ca}^{2+}$ influx through NMDARs is thought to play a central role in synaptogenesis, synaptic remodeling, and long-lasting forms of synaptic plasticity such as NMDARdependent long-term potentiation (LTP) (Constantine-Paton and Cline, 1998; Malenka and Nicoll, 1999). NMDARs are composed of NR1 and NR2 subunits, which cotranslationally assemble in the endoplasmic reticulum to form functional channels (Carroll and Zukin, 2002). Differential association of NR1 with the NR2A-D subunits confers differing physiological and pharmacological properties to NMDARs and regulates receptor trafficking and targeting to synaptic sites (Ozawa et al., 1998; Carroll and Zukin, 2002).

Synaptic NMDARs are concentrated in postsynaptic densities (PSDs), where they are structurally organized (and spatially restricted) in a large macromolecular signaling complex composed of kinases, phosphatases, and adaptor and scaffolding proteins

\footnotetext{
Received Sept. 11, 2003; revised Sept. 30, 2004; accepted 0ct. 1, 2004.

This work was supported by National Institutes of Health Grants NS20752 (R.S.Z.) and NS45287 (M.V.L.B.) and a generous grant from the F. M. Kirby Foundation. M.V.L.B. is the Sylvia and RobertS. Olnick Professor of Neuroscience We thank Dr. Michael D. Ehlers (Duke University School of Medicine, Durham, NC), Dr. Masayoshi Mishina (University of Tokyo, Tokyo, Japan), Dr. Shigetada Nakanishi (Kyoto University, Kyoto, Japan), and Dr. Stefano Vicini (Georgetown University Medical Center, Washington, DC) for NR1 and NR2 CDNAs, Morgan Sheng (Massachusetts Institute of Technology, Cambridge, MA) and David S. Bredt (University of California San Francisco, San Francisco, CA) for PSD-95 CDNAs, Reed C. Carroll for helpful comments on this manuscript, and Geoff Lau for technical assistance.

Correspondence should be addressed to Dr. R. Suzanne Zukin, Department of Neuroscience, Albert Einstein College of Medicine, 1300 Morris Park Avenue, Bronx, NY 10461. E-mail: zukin@aecom.yu.edu.

V. A. Skeberdis' present address: Laboratory of Membrane Biophysics, Institute of Cardiology, Kaunas University of Medicine, Sukileliu 7, 50009 Kaunus, Lithuania.

DOI:10.1523/JNEUROSCI.3159-04.2004

Copyright $\odot 2004$ Society for Neuroscience 0270-6474/04/2410138-11\$15.00/0
}

(Kennedy, 1997; Craven and Bredt, 1998; Garner et al., 2000; Scannevin and Huganir, 2000; Sheng, 2001). Scaffolding proteins serve to structurally organize and localize proteins to the PSD and physically link receptors such as NMDARs in close proximity to protein kinases, phosphatases, and other downstream signaling proteins. The PSD-95-synapse-associated protein-90 (SAP-90) subfamily of membrane-associated guanylate kinase (MAGUK) proteins are scaffolding proteins and major components of the PSD. PSD-95 and related MAGUKs contain three PSD-95, discs large, zona occludens-1 (PDZ) protein-protein interaction motifs, which mediate their binding to NMDARs (Niethammer et al., 1996), Shaker-type $\mathrm{K}^{+}$channels (Kim et al., 1995), cell adhesion molecules (Irie et al., 1997), and intracellular signaling enzymes (Brenman et al., 1996; Chen et al., 1998; Kim et al., 1998; Tezuka et al., 1999). PSD-95 enhances NMDAR clustering at synapses (Kim et al., 1996) and inhibits NR2-mediated internalization (Roche et al., 2001; Lavezzari et al., 2004). Although overexpression of PSD-95 accelerates maturation of excitatory synapses (El Husseini et al., 2000), reduces NMDAR desensitization (Li et al., 2003), and preferentially stabilizes NR1/NR2A (over NR1/NR2B) receptors (Losi et al., 2003), acute PSD-95 knockdown or disruption of the interaction between NMDARs and PSD-95 at cortical synapses uncouples synaptic NMDARs from downstream signaling molecules such as neuronal nitric oxide synthase (nNOS) (Sattler et al., 1999). Moreover, targeted truncation of the PSD-95 gene enhances NMDAR-dependent LTP, severely impairs spatial learning (Migaud et al., 1998), and disrupts visual cortical plasticity (Fagiolini et al., 2003), suggesting an important role for PSD-95 in synaptic plasticity. Studies involving targeted truncation of the C-terminal tails of the NR2A and NR2B subunits support their role in synaptic localization and clustering of NMDARs (Steigerwald et al., 2000). 
Although much is known about the identity of scaffolding proteins and their role in binding NMDARs, little is known about their actions on NMDAR function. The present study was undertaken to examine functional modulation of NMDARs by PSD95-SAP90. Here we show that PSD-95 expression regulates NMDA channel gating and trafficking. Experiments involving single-channel and whole-cell recording, surface Western blots, and immunofluorescence of live cells reveal that expression of PSD-95 increases surface expression and channel opening rates of NMDARs in Xenopus oocytes and human embryonic kidney (HEK)-293 cells. Experiments involving site-directed mutagenesis reveal that the PDZ binding motif in the NR2 C-terminal tail is critical to the action of PSD-95 on NMDARs. These findings indicate that scaffolding proteins can modulate channel gating and trafficking of intact, heteromeric NMDARs, mechanisms that may be important to synaptic plasticity.

\section{Materials and Methods}

Expression constructs. Rat NR1-1a $\left(\mathrm{NR}_{011}\right)$ cDNA and mouse 1 (corresponding to rat NR2A) cDNA in the pBluescript vector were gifts from Dr. S. Nakanishi (Kyoto University, Kyoto, Japan) and Dr. M. Mishina (The University of Tokyo, Tokyo, Japan), respectively. Rat NR1-1a and NR2A in the pRK5 vector were gifts from Dr. M. D. Ehlers (Duke University School of Medicine, Durham, NC). Yellow fluorescent protein (YFP)-tagged NR1-1a was a gift from Dr. S. Vicini (Georgetown University Medical Center, Washington, DC). PSD-95-green fluorescent protein (GFP) was a gift from Dr. D. S. Bredt (University of California San Francisco, San Francisco, CA). myc-tagged PSD-95 was a gift from Dr. M. Sheng (Massachusetts Institute of Technology, Cambridge, MA). cDNAs were subcloned into $\mathrm{pBluescript} \mathrm{S}(-)$ vectors for oocyte expression. Capped mRNAs were synthesized as runoff transcripts from linearized plasmid cDNAs with T3 or T7 polymerase (Ambion mMessage mMachine transcription kit; $2 \mathrm{hr}$ at $37^{\circ} \mathrm{C}$ ).

Single-channel recording from Xenopus oocytes. Selected stage V and VI oocytes from adult female Xenopus laevis (Xenopus I, Ann Arbor, MI) were injected with a mixture of in vitro-transcribed mRNAs (20 ng mRNA per cell; NR1/NR2 = 1:2) using a Nanoject injector (Drummond Scientific, Broomall, PA) as described previously (Zheng et al., 1999). PSD-95 was coexpressed by injection of PSD-95 mRNA (20 ng) at the time of or $24 \mathrm{hr}$ after injection of NMDAR mRNAs. Oocytes were maintained at $18^{\circ} \mathrm{C}$ in culture buffer containing (in $\mathrm{mM}$ ): $103 \mathrm{NaCl}, 2.5 \mathrm{KCl}, 2$ $\mathrm{MgCl}_{2}, 2 \mathrm{CaCl}_{2}, 5$ HEPES, $\mathrm{pH}$ 7.5. Single-channel currents were recorded from outside-out patches excised from devitellinized oocytes at 2-7 d after the last injection of mRNA as described previously (Lan et al., 2001). Pipette resistance was 7-12 $\mathrm{M} \Omega$ when filled with an internal solution consisting of (in mM): $115 \mathrm{CsCl}, 5.0$ EGTA, 10 HEPES, pH 7.2. Oocytes were perfused in external recording solution $\left(\mathrm{Mg}^{2+}\right.$-free, normal frog Ringer's solution) consisting of (in $\mathrm{mM}$ ): $116 \mathrm{NaCl}, 2.0 \mathrm{KCl}, 1.0 \mathrm{CaCl}_{2}, 10$ HEPES, pH 7.2. NMDA (100 $\mu \mathrm{m}$ with $1 \mu \mathrm{m}$ glycine) was delivered to the patch from a multibarrel array fed by gravity. Single-channel currents were filtered at $5 \mathrm{kHz}$ and digitized at $20 \mathrm{kHz}$. Single-channel current values were determined from means of Gaussian fits to all-point amplitude histograms. $n p_{\mathrm{o}}$ was calculated as the total channel open time divided by recording time. Open-time durations were calculated from single-channel openings above baseline, but presumably include events from two or more channels in the same patch. To construct currentvoltage $(I-V)$ relationships, single-channel currents were measured from each patch at potentials between -60 and $+60 \mathrm{mV}$ ( $20 \mathrm{mV}$ steps). Data are means \pm SEMs for 15-18 patches excised from different cells from a minimum of three independent experiments. Statistical significance was assessed by the Student's unpaired $t$ test (Sigma Plot 3.0) and ANOVA (CLR ANOVA 1.3).

Cell culture and transfection. HEK-293 and COS-7 cells were maintained in DMEM (Invitrogen, Grand Island, NY) plus 10\% fetal calf serum, $20 \mathrm{~mm}$ glutamine, and $100 \mathrm{U} / \mathrm{ml}$ penicillin and streptomycin at $37^{\circ} \mathrm{C}$ in $5 \% \mathrm{CO}_{2}$ and were split twice weekly. For transfection, HEK-293 cells were plated at a density of $1 \times 10^{6}$ cells per milliliter on $12 \mathrm{~mm}$ glass coverslips coated with poly-D-lysine $(10 \mu \mathrm{g} / \mathrm{ml})$ in 24-well culture plates (Falcon) and transfected with wild-type or mutant NR1/NR2A-GFP or PSD-95-GFP plasmid ( $1 \mu \mathrm{g}$ of plasmid cDNA per $12 \mathrm{~mm}$ coverslip for electrophysiology or $16 \mu \mathrm{g}$ of cDNA per $10 \mathrm{~cm}$ culture plate for Westerns at a ratio of 1:1:1) using the calcium-phosphate method according to the manufacturer's protocol (Calcium Phosphate Transfection System, Invitrogen). For internalization experiments, COS cells were transfected with YFP-NR1 and wild-type or mutant NR2A in the absence or presence of myc-tagged PSD-95 ( $1 \mu \mathrm{g}$ of plasmid cDNA per $12 \mathrm{~mm}$ glass coverslip at a ratio of 1:1:1) using LipofectAMINE 2000 Transfection Reagent (Invitrogen) according to the manufacturer's protocol. The transfection mixture was replaced 4-6 hr later with fresh culture medium containing DL-2-amino-5-phosphonopentanoic acid (D,L-AP-5; 1 $\mathrm{mm}$; Tocris, Ellisville $\mathrm{MO}$ ). Cells were maintained at $37^{\circ} \mathrm{C}$ in $5 \% \mathrm{CO}_{2}$ for 1-2 $\mathrm{d}$ before recording or processing for Western blot analysis and internalization assays. Transfected cells were identified by their green fluorescence under a fluorescence microscope at $488 \mathrm{~nm}$.

Whole-cell recording from HEK-293 cells. Electrophysiological recordings were performed $1-2 \mathrm{~d}$ after transfection. Rapid agonist application was achieved by placing cells in a laminar solution stream that was delivered from a multibarrel array fed by gravity and moved laterally by a Piezo electric device, which achieved changes of solutions in $<100 \mathrm{msec}$. Currents activated by NMDA $(300 \mu \mathrm{M})$ in the presence of glycine $(10 \mu \mathrm{M})$ were recorded in the whole-cell mode at a holding potential of $-60 \mathrm{mV}$, filtered at $20 \mathrm{~Hz}$, and digitized on-line at $100 \mathrm{~Hz}$ as described previously (Zheng et al., 1999). Electrodes with open-tip resistances of 2-5 M $\Omega$ were used. Data were acquired and analyzed using pClamp 6 software and GeneClamp 500 amplifier (Axon Instruments, Foster City, CA). The internal pipette solution was composed of (in mM): $145 \mathrm{KCl}, 4 \mathrm{Mg}$-ATP, 10 HEPES, and 5.5 EGTA, adjusted to $\mathrm{pH} 7.25$ with $\mathrm{KOH}$. Cells were perfused continuously at room temperature with external bath solution that contained (in mM): $145 \mathrm{NaCl}, 5.4 \mathrm{KCl}, 1 \mathrm{CaCl}_{2}, 11$ glucose, and 10 HEPES, adjusted to pH 7.3 with $\mathrm{NaOH}$. For $\mathrm{Ca}^{2+}$-free solution, $1 \mathrm{~mm}$ $\mathrm{BaCl}_{2}$ was added to replace $\mathrm{CaCl}_{2}$.

Channel insertion. To measure the effects of PSD-95 on NMDA channel insertion, we used the quasi-irreversible NMDAR open-channel blocker, MK-801. To block functional NMDARs present at the cell surface, we applied MK-801 ( $5 \mu \mathrm{M}$ ) in the presence of NMDA (1 mM with 50 $\mu \mathrm{M}$ glycine) to HEK-293 cells expressing NMDARs in the absence and presence of PSD-95. Because block by MK-801 is irreversible within the time frame of the experiment (Rosenmund et al., 1995), the recovery of NMDA responses after block by MK- 801 is indicative of newly inserted channels at the cell surface. After washout of MK-801 and NMDA, test applications $(5 \mathrm{sec})$ of NMDA ( $1 \mathrm{~mm}$ with $50 \mu \mathrm{M}$ glycine) were given at indicated times, and NMDA-elicited currents were recorded.

Western blot analysis of surface proteins. Live HEK-293 cells expressing NMDARs in the absence or presence of PSD-95 were washed twice and reacted for $30 \mathrm{~min}$ at $4^{\circ} \mathrm{C}$ with NHS-SS (sulfosuccinimidyl 2-(biotinamido)-ethyl-1,3-dithiopropionate)-biotin ( $1.5 \mathrm{mg} / \mathrm{ml}$; Pierce, Rockford, IL) to biotinylate surface proteins as described previously (Chen et al., 1999; Lan et al., 2001). Cell extracts containing equal amounts of protein were incubated for $2 \mathrm{hr}$ at $4^{\circ} \mathrm{C}$ with Neutravidin-linked beads (Pierce) to capture biotinylated surface protein. Bound proteins were eluted from Neutravidin beads by incubation with SDS-PAGE gel loading buffer containing DTT (which releases the biotin moiety from labeled proteins) and subjected to gel electrophoresis. Immunoblotting was performed with either (1) a monoclonal antibody directed against an extracellular epitope (amino acids 660-811) of the rat NR1 subunit $(1.4 \mu \mathrm{g} /$ $\mathrm{ml}$; gift from Dr. Morrison, Mt. Sinai School of Medicine, New York, NY) or (2) a polyclonal antibody directed to a sequence within the intracellular C-terminal tail of the NR2A subunit (Upstate Biochemicals, Lake Placid, NY) overnight at $4^{\circ} \mathrm{C}$. For samples of total cell protein, band intensities were normalized to those for actin, which was used as a loading control. In the case of NR1 and NR2A protein expression in the surface fraction, we performed equal loading of samples, because actin is not expressed at the cell surface. In some experiments, immunoblots were processed by a standard chemiluminescence protocol. Bands were digitized and quantified using a Scan Jet 4-C computing densitometer equipped with NIH Image 1.61 image-analysis software. In a second set 
of experiments, immunoblots were imaged directly and analyzed using a Kodak Image Station 200R equipped with Kodak ID Image Analysis software (Eastman Kodak, Rochester, NY). Band intensities for samples from cells expressing NMDARs in the presence of PSD-95 were normalized to the corresponding band intensities for samples from cells expressing wild-type NMDARs only. Mean band densities were statistically analyzed with a Student's unpaired $t$ test to determine significance.

NMDAR internalization. Immunofluorescence was performed on live COS-7 cells expressing wild-type or mutant NMDARs (YFPtagged NR1/NR2A) in the absence or presence of myc-tagged PSD-95 at 1-2 d after transfection. To measure the rate of NMDAR internalization, intact (live) cells were labeled with chick anti-GFP polyclonal antibody, which recognizes YFP (1:200; Chemicon, Temecula, CA), for $1 \mathrm{hr}$ at $4^{\circ} \mathrm{C}$. To visualize surface receptors, cells were washed three times with PBS, fixed with $4 \%$ paraformaldehyde $/ 2 \%$ sucrose, washed again, and labeled with donkey antichick Cy3-conjugated secondary antibody (1: 300; Jackson ImmunoResearch, West Grove, PA) for $30 \mathrm{~min}$ at room temperature.

To assess the rate of receptor internalization, antibody-labeled cells were maintained at $37^{\circ} \mathrm{C}$ for 0,15 , or 30 min in DMEM medium containing $1 \mathrm{~mm}$ D,L-AP-5. At indicated times, antibody-labeled cells were chilled in ice-cold PBS to halt receptor trafficking and "acidstripped" by exposure to $0.5 \mathrm{M} \mathrm{NaCl}-0.2 \mathrm{M}$ acetic acid for $4 \mathrm{~min}$ at $4^{\circ} \mathrm{C}$ (Carroll et al., 1999). This procedure selectively strips bound antibody from the cell surface and leaves internalized antibody-receptor complexes intact. To detect acid-resistant immunoreactivity corresponding to internalized receptors, cells were washed three times with ice-cold PBS, fixed in paraformaldehyde-sucrose, permeabilized with $0.2 \%$ Triton X-100 in PBS containing 0.5\% BSA, and labeled with donkey anti-chicken Cy3conjugated secondary antibody. To monitor PSD-95 expression, cells were labeled with an anti-myc monoclonal antibody (1:1000; Stressgen Biotechnologies Corporation, Victoria, British Columbia, Canada), followed by donkey anti-mouse Cy5-conjugated secondary antibody (1: 200; Jackson ImmunoResearch). Surface and intracellular images were viewed through an Olympus Provis epifluorescent microscope and captured with a SPOT RT CCD-cooled camera with diagnostic software version 3.0. Images were quantified with MetaMorph Imaging System (Universal Imaging Corporation, Downingtown, PA).

Peptide blockers. The amino acid sequence for NR2A-C10, corresponding to the distal portion C-terminal tail of the NR2A subunit, was KKMPSIESDV. As a control, a peptide containing the same amino acids in a randomized order (VKDSMEKISP) was used. All custom-made peptides were prepared and purified by reverse-phase HPLC by SigmaGenosys (The Woodlands, TX). Peptides (1 mM) were dissolved in the internal solution described above and delivered via the recording patch pipette.

\section{Results}

PSD-95 increases NMDA channel open probability but not conductance or open time

To examine the effects of PSD-95 on NMDA channel gating and surface expression, we recorded channel activity in outside-out patches excised from Xenopus oocytes expressing NR1-1a/NR2A $\left(\mathrm{NR} 1_{011} / \mathrm{NR} 2 \mathrm{~A}\right)$ receptors in the presence or absence of PSD-95.
Xenopus oocytes provide geometric simplicity and enable analysis of a homogeneous population of NMDARs. NR1-1a/NR2A receptors are a major NMDAR subtype expressed at excitatory synapses of hippocampal neurons (Tovar and Westbrook, 1999).

In control patches, NMDA $(100 \mu \mathrm{M})$ activated channels with a single-channel conductance, $\gamma=47.6 \pm 1.1 \mathrm{pS}(n=5)$ at -60 $\mathrm{mV}$ that did not vary with voltage (Fig. $1 a, d$ ). NMDA channel activity in patches excised from oocytes coexpressing PSD-95 was markedly enhanced (Fig. 1a,b). Coexpression of PSD-95 increased the number of active channels times channel open probability, $n p_{\mathrm{o}}$ (calculated as total channel open time divided by recording time), by $\sim 3.1$-fold from $0.066 \pm 0.013$ in the absence of PSD-95 $(n=15)$ to $0.209 \pm 0.037$ in the presence of PSD-95 $(n=18 ; p<0.005)$ (Fig. $1 a-c)$. Because PSD-95 expression could alter membrane properties and therefore alter patch size, we monitored patch membrane capacitance, which is proportional to the membrane content of the patch. PSD-95 expression did not detectably alter patch membrane capacitance (cells expressing NMDAR, $11.21 \pm 0.26 \mathrm{pF}(n=7)$; cells expressing NMDAR + PSD-95, $10.57 \pm 0.48 \mathrm{pF}(n=7)$ (Fig. $1 g)$, indicating that PSD-95 did not produce a consistent change in the membrane area of excised patches. Moreover, PSD-95 expression did not alter NMDA single-channel conductance $(\gamma=46.8 \pm 0.9 \mathrm{pS}$ in the presence of PSD-95 $(n=5)$ vs $47.6 \pm 1.1 \mathrm{pS}$ in the absence of PSD-95 ( $n=5$; not statistically significant) measured at $-60 \mathrm{mV}$ 


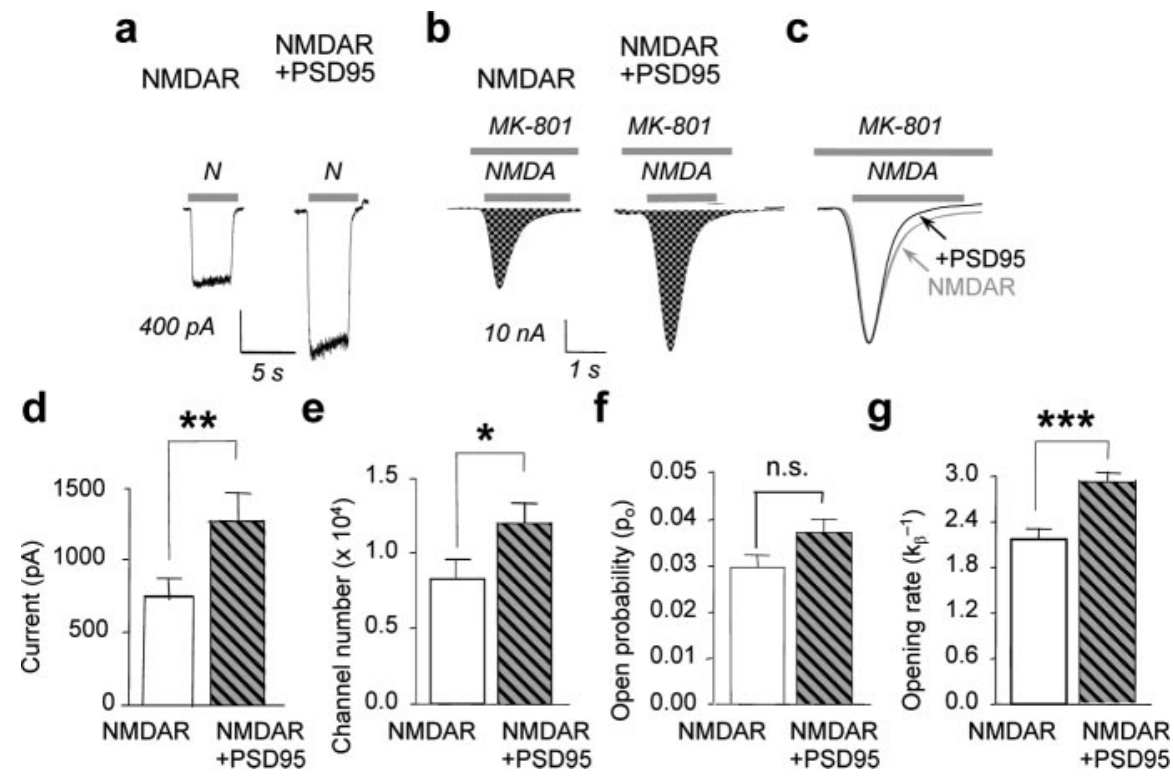

Figure 2. PSD-95 increases NMDA channel opening rate and surface expression. $a$, Sample records of NMDA-elicited currents recorded from HEK-293 cells expressing NR1-1a/NR2A receptors in the absence (left) and presence (right) of PSD-95. Whole-cell currents were elicited by application of NMDA (300 $\mu \mathrm{m}$ with $10 \mu \mathrm{m}$ glycine) via the bath perfusate and were recorded in the whole-cell patch-clamp configuration in $\mathrm{Ca}^{2+}$-free $\left(\mathrm{Ba}^{2+}\right)$ Ringer's solution. $V_{\mathrm{h}}=-60 \mathrm{mV}$. Coexpression of PSD-95 increased the initial peak amplitude of NMDA-elicited whole-cell currents ( $/$ ). $b$, Sample records of NMDA-elicited currents in the continuous presence of the open-channel blocker MK-801 (5 $\mu \mathrm{m})$ from HEK-293 cells expressing NMDARs in the absence (left) and presence (right) of PSD-95. Currents were elicited by application of NMDA (1 mM NMDA with $50 \mu$ m glycine). $V_{\mathrm{h}}=-60 \mathrm{mV}$. The NMDA inward current increased to a peak value and then decayed exponentially because of MK-801 block of NMDA channels as they opened. The cumulative charge transfer, $Q$, which is the total current flow during the time interval for complete block by MK-801, was obtained by integration of the current trace over time (area indicated by checkerboard pattern). PSD-95 increased the number of functional NMDA channels expressed at the cell surface, $N$, as indicated by the larger integrated current in cells expressing PSD-95. c, Agonist-evoked currents in $b$ were normalized to the same peak amplitude for comparison of the time course of decay. The more rapid decay of the NMDA current observed in the presence of PSD-95 indicates a higher rate of channel opening, $k_{\alpha} \cdot d-g$, Quantitation of data in $a-c . d$, Potentiation of NMDA whole-cell current: $I_{\text {control }}=688 \pm 134 \mathrm{pA}(n=28), I_{\text {PSD }}=1275 \pm 140$ $\mathrm{pA}(n=38)$; the ratio of the current in the presence of PSD-95 $(n=26)$ to that in the absence of PSD-95 $(n=22)$ was $1.85 \pm 0.2$ $(p<0.05)$. $e$, The channel number, $N$, for HEK-293 cells expressing NMDARs in the absence and presence of PSD-95 for a given batch of HEK-293 cells was normalized to the mean NMDA-elicited whole-cell current in the absence of PSD-95, which corrects for differences in levels of expression among batches of cells. The ratio of the number of functional channels expressed at the surface of cells expressing NMDARs in the presence of PSD-95 $(n=26)$ to that in the absence of PSD-95 $(n=22)$ was $1.48 \pm 0.1$ ( $p<$ 0.05). $f$, The ratio of the channel open probability in the presence of PSD-95 $(n=26)$ to that in the absence of PSD-95 $(n=22)$ was $1.25 \pm 0.2$ (not significant). $g$, The ratio of the opening rates, $k_{\alpha}$, for cells expressing NMDARs in the presence of PSD-95 $(n=22)$ to that in the absence of PSD-95 was $1.3 \pm 0.1(n=22 ; p<0.005)$.

or the reversal potential, as evidenced by comparison of $I-V$ relationships recorded in the absence of $\mathrm{Mg}^{2+}\left(E_{\text {rev }} \sim 0 \mathrm{mV} ; n=5\right)$ (Fig. 1d). Expression of PSD-95 did not significantly change the mean duration of opening $(5.55 \pm 0.18 \mathrm{msec}$ in the presence of PSD-95 vs $5.62 \pm 0.41$ msec in the absence of PSD-95; $n=5$; not significant) (Fig. 1e,f). The distribution of open times was fit by a single exponential consistent with the presence of a single open state $[\tau=5.62 \pm 0.4 \mathrm{msec}$ in the absence of PSD-95 $(n=5)$ vs $\tau=$ $5.55 \pm 0.18 \mathrm{msec}$ in the presence of PSD-95 $(n=5$; not significant] (Fig. 1e,f). The finding that PSD-95 did not alter NMDA channel mean open time is consistent with findings by Losi et al. (2003) involving analysis of NMDA synaptic currents in cerebellar granule cells transfected with PSD-95.

\section{PSD-95 increases channel opening rate and delivers new channels to the surface}

The results reported thus far suggest that PSD-95 expression increases NMDA channel open probability and/or number of active channels at the cell surface. To analyze independently the effects of PSD-95 on the number of functional channels in the membrane, $N$, and channel open probability, $p_{\mathrm{o}}$, we used a method that takes advantage of the essentially irreversible block of NMDA-elicited currents by the openchannel blocker MK-801 (Jahr, 1992; Rosenmund et al., 1995). We recorded NMDA-elicited whole-cell currents from HEK-293 cells expressing NR1-1a/NR2A receptors in the absence (Fig. $2 a$, left) or presence (Fig. $2 a$, right) of PSD-95. Coexpression of PSD-95 increased NMDAelicited whole-cell current, $I$, by approximately twofold. To determine the number of channels per cell, $N$, we recorded NMDA-elicited currents in the continuous presence of MK-801 ( $5 \mu \mathrm{M})$ from the two sets of cells and measured charge transfer, $Q$, which is the total current flow during application of NMDA and block of the NMDA-elicited current by MK-801 (Fig. 2b). $N$ can be calculated from $Q$, as follows: $N=Q /\left[\gamma\left(V-E_{\text {rev }}\right) t_{\mathrm{b}]}\right]$, where $\gamma$ is the single-channel conductance, $(V-$ $\left.E_{\text {rev }}\right)$ is the driving force, and $t_{\mathrm{b}}$ is the time constant for MK-801 block of open channels $\left[t_{\mathrm{bl}}=1 /\left(k_{\mathrm{bl}}[\mathrm{MK}-801]\right)\right.$, where $k_{\mathrm{bl}}$, the rate constant for MK-801 block, $=2.5 \times$ $10^{7} / \mathrm{M} / \mathrm{sec}$ (Jahr, 1992)]. For HEK-293 cells expressing NMDARs in the absence of PSD-95, the mean number of channels per cell, $N_{\text {control }}$, was $8.4 \pm 0.12 \times 10^{3}(n=$ 26). PSD-95 expression does not detectably alter single-channel conductance in Xenopus oocytes (Fig. 1c-e) and does not change the affinity of NMDARs for MK801 at high concentrations of agonist (Rutter and Stephenson, 2000). Hence, PSD-95 should not affect $k_{\mathrm{bl}}$. The channel number, $N$, for cells expressing NMDARs in the absence or presence of PSD-95 was normalized to $I_{\text {control }}$, the mean value of the NMDA-elicited whole-cell current in the absence of PSD-95 for a given batch of cells, which corrects for any differences in levels of expression between batches of cells. Thus, we calculated that PSD-95 expression increased the number of channels per cell by $\sim 1.5$-fold $\left(N_{\text {PSD-95 }} / N_{\text {control }}=1.48 \pm 0.13 ; n=22 ; p<0.05\right)$ (Fig. $\left.2 b, e\right)$, a value that accounted for a major component of, but not all of the increase in, whole-cell current $\left(I_{\mathrm{PSD}} / I_{\text {control }}=1.85 \pm 0.2 ; n=28\right.$ and 30, respectively; $p<0.05$ ) (Fig. $2 d$ ). $p_{\mathrm{o}}$ in cells expressing NMDARs in the absence and presence of PSD-95 can be calculated from the near steady-state current at the peak of the NMDA-elicited whole-cell current, $I$, the single-channel current, $i$, and $N$, as follows: $p_{\text {o, control }}=I_{\text {control }} / \mathrm{i}_{\text {control }}=0.030 \pm 0.003$, $p_{\mathrm{o}, \mathrm{PSD}}=I_{\mathrm{PSD}} / \mathrm{i} N_{\mathrm{PSD}}=0.037 \pm 0.003$, from which the ratio $p_{\mathrm{o}}$, $\mathrm{PSD} / p_{\mathrm{o} \text {, control }}=1.25$ (Fig. $2 f$ ). These findings indicate that PSD-95 increased the number of active NMDA channels in the HEK-293 cell surface and may also increase channel open probability, although the small increase in this parameter did not achieve significance.

As an independent measure of the effect of PSD-95 on NMDA channel gating, we analyzed the rate of decay of NMDA-elicited 
current in the presence of MK-801 (Fig. 2c). Provided that $k_{\mathrm{bl}}[\mathrm{MK}-801] \gg k_{\alpha}$ and $k_{\beta}$ (the closing and opening rates, respectively), the later course of decay can be described by a single exponential with the rate constant, $k_{\beta}$ (Rosenmund et al., 1995). Expression of PSD-95 increased $k_{\beta}$ (from $2.38 \pm 0.10 \mathrm{sec}^{-1}$ for control cells to $3.01 \pm 0.13 \mathrm{sec}^{-1}$ for PSD-95-expressing cells; $n=26$ and 22, respectively; $p<0.001$ ) (Fig. $2 g$ ). From measurements of $p_{\mathrm{o}}$ and $k_{\beta}$, and the relation, $p_{\mathrm{o}}=k_{\beta} /\left(k_{\alpha}+k_{\beta}\right)$, we calculated values of $k_{\alpha}=77 \pm 4 \mathrm{sec}^{-1}$ in the absence of PSD-95 versus $78 \pm 7 \mathrm{sec}^{-1}$ for cells expressing PSD-95. This difference was not significant. Thus, PSD-95 increases NMDA channel opening rate, with little effect on closing rate.

The PDZ binding motif in NR2A is critical to PSD-95-induced potentiation of NMDA currents

NMDARs bind scaffolding proteins such as PSD-95 via a four amino acid PDZ-recognition motif (ESDV) present at the distal end of the C-terminal tails of the NR2A and NR2B subunits (Kornau et al., 1995; Niethammer et al., 1996). To examine whether the effects of PSD-95 on NMDAR trafficking and gating are caused by a direct binding interaction between NMDAR and PSD-95, we performed two experiments. First, we deleted the PDZ binding motif in the NR2A subunit by site-directed mutagenesis. We recorded NMDA-elicited currents in cells expressing the wild-type NR1-1a/NR2A receptors or NR1-1a/ NR2A $\triangle E S D V$ receptors in the absence and presence of PSD-95GFP. In cells expressing wild-type receptors, application of NMDA (with glycine) elicited inward, desensitizing currents (Fig. 3a, first trace). Coexpression of PSD-95 increased NMDA currents (Fig. $3 a$, second trace, $b$ ). Removal of the PDZ binding motif in the NR2A subunit greatly reduced basal NMDA-elicited currents in the absence (Fig. $3 a$, third trace) or presence (Fig. $3 a$, fourth trace) of PSD-95. This finding is consistent with the observation that targeted deletion of the distal portion of the $\mathrm{C}$ terminus of NR2A (containing the PDZ binding motif ESDV) in mice greatly reduces synaptic NMDAR currents, with little or no effect on extrasynaptic NMDARs (Steigerwald et al., 2000). Moreover, deletion of the ESDV motif essentially abolished potentiation of NMDA currents by PSD-95 (Fig. $3 a$, fourth trace, $b$ ). This finding indicates that the PDZ binding motif in the NR2A C-terminal tail is critical for the effects of PSD-95 on NMDAR functional properties.

Our finding that removal of the ESDV motif in the NR2A subunit causes greatly reduced NMDA responses in the absence of PSD-95 expression could occur because of a change in an intrinsic channel property and/or loss of binding by an endogenous PDZ protein such as SAP-102 (Sans et al., 2003). To address this issue, we expressed mutant NR1/NR2A $\triangle E S D V$ receptors in Xenopus oocytes and recorded NMDA-elicited currents. In oocytes (as in HEK-293 cells), the mutant receptors exhibited greatly diminished NMDA currents, which were unaltered by PSD-95. The finding of greatly diminished responses in the two cell types suggests that the "defect" is intrinsic to the channel.

Next, we examined the ability of a 10 amino acid peptide corresponding to the distal portion C-terminal tail of the NR2A subunit (NR2A-10C) to alter NMDA-elicited currents in HEK293 cells expressing wild-type NR1-1a/NR2A receptors in the presence of PSD-95 (Fig. 3c, filled circles). The advantages of the peptide experiment are twofold. First, it enables investigation of the receptor in its native (wild-type) configuration. Second, it enables investigation of the effects of acute disruption of the interaction between the receptor and all PDZ proteins (PSD-95 and endogenous PDZ proteins such as SAP-102). NR2A-C10 mark- a
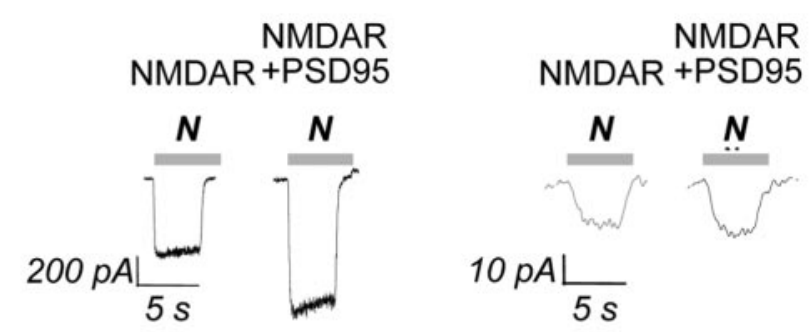

b
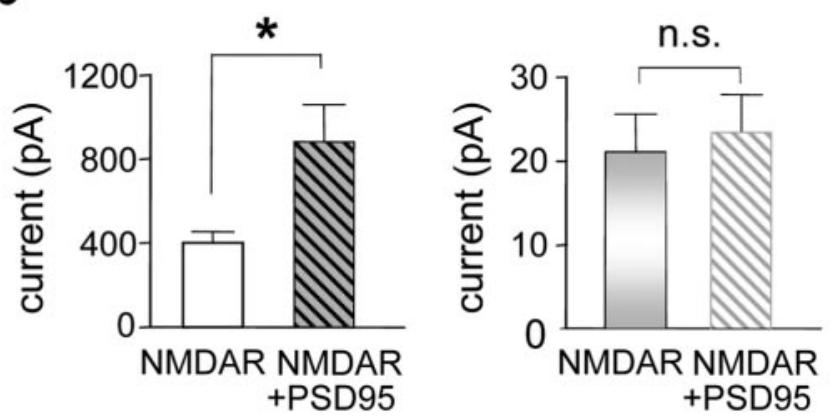

C

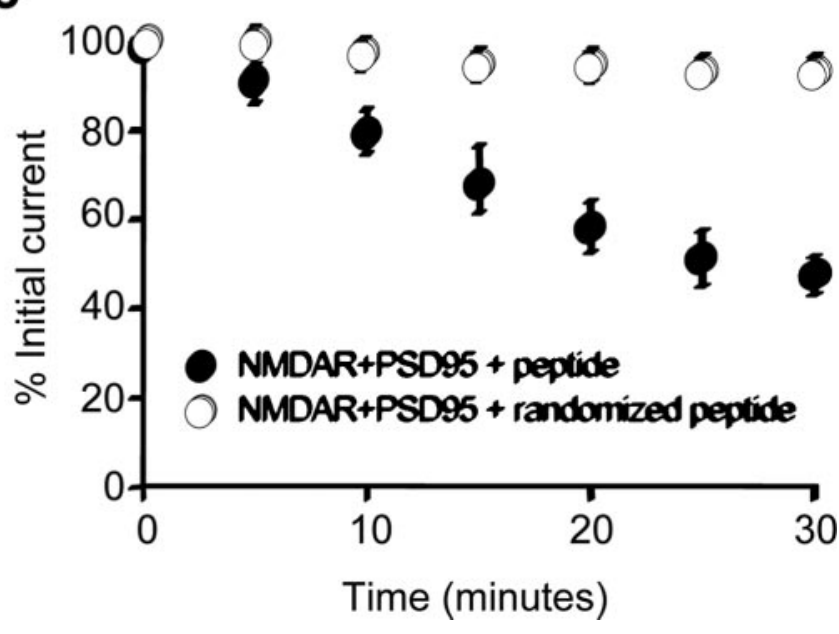

Figure 3. The PDZ binding motif in NR2A is critical to PSD-95 potentiation of NMDA currents. Whole-cell recordings were obtained from HEK-293 cells expressing wild-type NR1-1a/NR2A receptors and mutant NR1-1a/NR2A $\triangle$ ESDV receptors in $\mathrm{Ca}^{2+}$-free $\left(\mathrm{Ba}^{2+}\right)$ Ringer's solution. Whole-cell currents were elicited by application of NMDA ( $300 \mu \mathrm{m}$ with $10 \mu \mathrm{m}$ glycine) via the bath-perfusate. $V_{\mathrm{h}}=-60 \mathrm{mV} . a, b$, PSD-95 increased NMDA-elicited whole-cell currents in cells expressing wild-type receptors (left) but did not detectably alter NMDA currents in cells expressing truncated mutant receptors (right). $c$, A peptide corresponding to the last 10 amino acids of the NR2A subunit C-terminal tail significantly inhibited NMDA-elicited currents in HEK293 cells expressing wild-type NR1a/NR2A receptors in the presence of PSD-95; a randomized peptide with the same amino acid composition did not detectably alter NMDA currents, indicating the specificity of the inhibition. NR2A-C10 also reduced NMDA-elicited currents in cells expressing NMDARs in the absence of transfected PSD-95, but at a slower rate than observed for cells expressing NMDARs and PSD-95.

edly reduced NMDA-elicited currents over $30 \mathrm{~min}$. In contrast, a randomized peptide with the same amino acid composition as that contained in NR2A-10C did not detectably alter NMDA currents by $30 \mathrm{~min}$, indicating the specificity of the inhibition by NR2A-10C (Fig. 3c, open circles). NR2A-C10 also reduced NMDA-elicited currents in cells expressing NMDARs in the absence of transfected PSD-95, but at a slower rate than observed for cells expressing NMDARs and PSD-95 (Fig. 3c, gray circles), consistent with the notion that adherent mammalian cells such as 
a

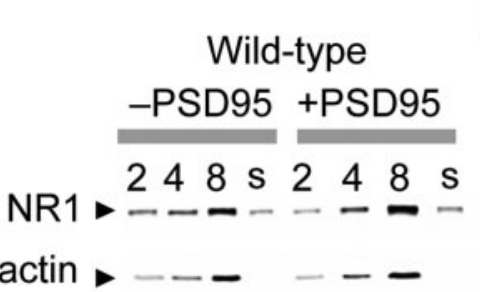

C

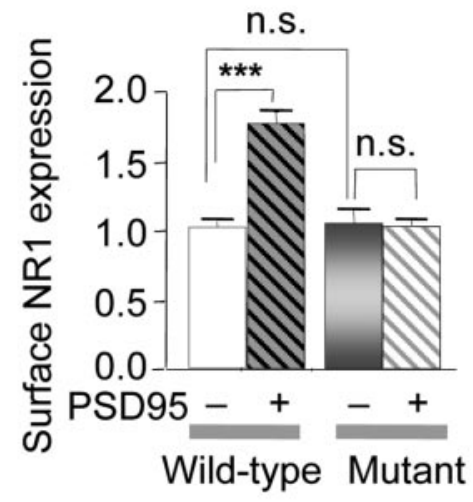

e
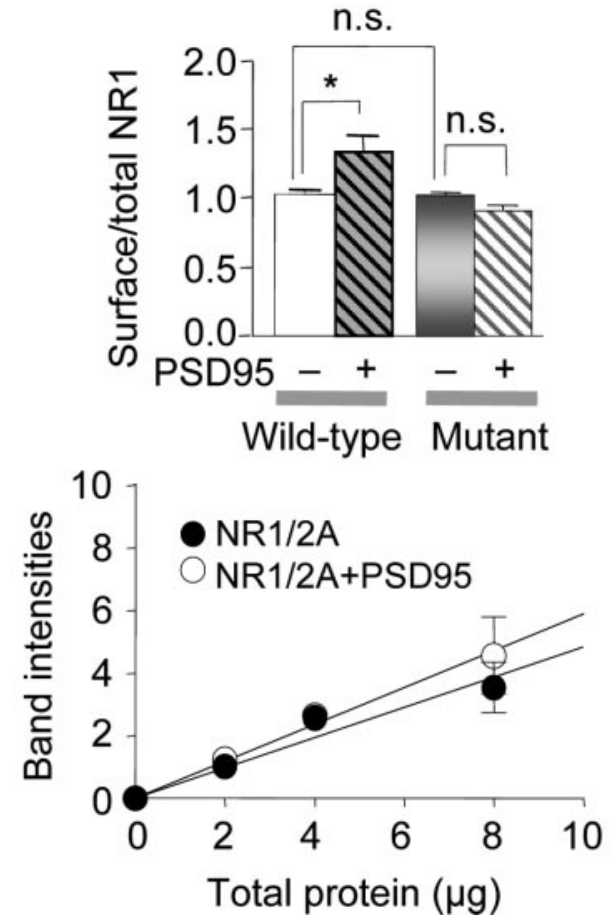

Figure 4. PSD-95 increases NR1 surface expression. NR1 surface and total cell expression in HEK-293 cells expressing wild-type NR11a/NR2A receptors and mutant NR1-1a/NR2A $\triangle$ ESDV receptors in the absence and presence of PSD-95, as assessed by Western blot analysis of biotinylated surface proteins, are shown. HEK-293 cells expressing NMDARs in the absence and presence of PSD-95 were biotinylated, lysed, isolated with Neutravidin beads, treated with DTT, and subjected to gel electrophoresis. Western blots were probed with anti-NR1 antibody 54.1. a, Representative Western blots of total $(2,4$, and $8 \mu \mathrm{g})$ and surface $(s)$ protein $(8 \mu \mathrm{g})$ from cells expressing wild-type NMDARs in the absence and presence of PSD-95. "Total" refers to cell extract before Neutravidin bead extraction; "surface" refers to Neutravidin bead-isolated protein. $b$, Representative Western blots of surface and total protein for wild-type and mutant NMDARs. $c_{\text {, }}$ Summary of data for wild-type and mutant NMDARs in the absence and presence of PSD-95 from Western blots like that shown in $a$ and b. PSD-95 increased NR1 abundance in samples of surface protein from cells expressing wild-type NMDARs to $1.75 \pm 0.07$-fold times that of control $(n=16 ; p<0.001)$. PSD-95 did not detectably alter NR1 abundance in samples of surface protein obtained from cells expressing mutant NMDARs. $d$, Total NR1 in cells expressing wild-type (left) or mutant (right) NMDARs in the absence and presence of PSD-95. For quantitation, values for $8 \mu \mathrm{g}$ samples were used. PSD-95 increased total NR1 protein in cells expressing wild-type NMDARs to $1.31 \pm 0.09$-fold times that of control $(n=16 ; p<0.005)$. PSD-95 did not detectably alter total NR1 abundance in cells expressing mutant NMDARs. e, PSD-95 increased the surface/total ratio to $1.26 \pm 0.09$-fold times that of control $(n=16 ; p<0.01)$ in the case of wild-type but not mutant NMDARs. $f$, Analysis of standards containing varying protein concentrations indicated that optical densities of bands were linearly related to protein concentration.
HEK-293 express endogenous PDZcontaining proteins (Sans et al., 2003).

\section{PSD-95 increases NMDAR} surface expression

The electrophysiological experiments presented thus far argue for a PSD-95mediated increase in the number of functional NMDARs on the cell surface. To measure directly whether coexpression of PSD-95 alters NMDAR subunit surface expression, we performed cell-surface Western blots as described previously (Lan et al., 2001). Intact HEK-293 cells expressing NR1-1a/NR2A receptors in the absence or presence of PSD-95 were surface labeled with sulfo-NHS-SS-biotin, and biotinylated surface proteins were separated from nonlabeled intracellular proteins by reaction with Neutravidin beads. Surface and total cell proteins were treated with DTT (which releases the biotin moiety from surface proteins), subjected to electrophoresis, and probed with monoclonal antibody 54.1 directed to an extracellular epitope in the NR1 subunit (Fig. 4a). Analysis of band intensities indicated an increase in surface NR1 expression to $1.75 \pm$ 0.07 -fold ( $n=16 ; p<0.001)$ (Fig. $4 c)$, an increase in total cell NR1 protein to $1.31 \pm$ 0.09 -fold ( $n=16 ; p<0.005$ ) (Fig. $4 d$ ), and an increase in the fraction of receptors at the cell surface to $1.26 \pm 0.09$-fold $(n=16$; $p<0.01$ ) (Fig. 4e). Similar results were observed when Western blots were reprobed with the NR2A antibody (increase in surface protein to $1.97 \pm 0.10 ; n=9$; $p<0.001$; increase in the total protein to $1.43 \pm 0.09$-fold; $n=9 ; p<0.01$; and increase in the surface/total to $1.48 \pm 0.11$ fold; $n=9 ; p<0.01$ (data not shown) (Table 1). The specificity of the biotinylation reaction was confirmed by reprobing Western blots for actin; actin immunoreactivity was present in the total cell protein but not in the surface protein fraction (Fig. $1 a, b)$. Protein standard curves verified that band intensities were within the linear range (Fig. $4 f$ ). The increase in total cell NMDAR expression is consistent with findings of others that PSD-95 enhances total protein abundance of NR1-1a/NR2A receptors in Xenopus oocytes (Yamada et al., 1999) and NR1-4b/NR2A receptors in HEK-293 cells (Rutter and Stephenson, 2000; Rutter et al., 2002) and suggests that the increase in the number of functional channels at the cell surface assessed electrophysiologically occurs, at least in part, via increased synthesis of new receptor subunits and/or decreased receptor degradation.

To examine whether the effects of PSD-95 on NMDAR surface expression 
Table 1. Summary of data for modulation of NMDARs by PSD-95

\begin{tabular}{lll}
\hline Parameter & PSD effect & Cell type \\
\hline$n p_{0}^{a}$ & 2.9-fold increase & Xenopus 00cytes \\
$l^{b}$ & 1.85 -fold increase & HEK-293 \\
$k_{\beta}{ }^{b}$ & 1.3 -fold increase & HEK-293 \\
$N^{b}$ & 1.48 -fold increase & HEK-293 \\
Surface expression $^{c}$ & 1.75 -fold increase-NR1Ab 1.97-fold increase- & HEK-293 \\
& NR2A Ab & \\
Insertion rate $^{d}$ & 2.5 -fold increase & HEK-293 \\
Internalization rate $^{e}$ & 2.2-fold decrease & COS-7 \\
\hline
\end{tabular}

The number of channels per patch times channel open probability, $n p_{0}$, was measured by recording of NMDA single channels in outside-out patches excised from Xenopus oocytes expressing recombinant NMDARs in the absence or presence of PSD-95. The channel opening rate, $k_{\beta}$, was calculated from the decay of the NMDA-elicited whole-cell current in the presence of MK-801 (Rosenmund et al., 1995). The number of functional channels expressed at the cell surface, $N$, was calculated from the cumulative charge transfer, $Q$ (total current flow during block by MK-801). For surface expression measurements, samples of surface and total protein were subjected to gel electrophoresis; Western blots were probed with antibodies to either the NR1 or NR2A subunits. The number of channels inserted per unit of time was estimated from the rate of recovery of the NMDA-elicited current after block of surface channels by MK-801. For internalization measurements, surface receptors were visualized by immunolabeling of live cells; internalized receptors were detected after acid stripping to remove surface receptors from antibody-labeled cells. Ab, Antibody.

${ }^{a}$ Single-channel recording from excised outside-out patches.

${ }^{b}$ Whole-cell patch-clamp recording of NMDA-elicited currents in the presence of MK-801.

Western blot analysis of biotinylated and total protein.

${ }^{d}$ Whole-cell patch-clamp recording of the recovered NMDA response after block by MK-801.

${ }^{e}$ Immunofluorescence of surface and internalized receptors.

were caused by a direct binding interaction between NMDAR and PSD-95, we examined the effect of PSD-95 on surface expression of the NR1a/NR2A truncation mutant. We performed a cell-surface biotinylation assay for cells expressing NR1/ $\mathrm{NR} 2 \mathrm{~A} \Delta \mathrm{ESDV}$ receptors in the absence or presence of GFP-PSD95. Surprisingly, removal of the PDZ binding motif in the NR2A subunit did not significantly alter basal cell-surface expression of NMDARs in the absence of PSD-95 (Fig. 4b) despite greatly reduced currents (Fig. $3 a, b$ ); however, removal of the PDZ binding motif did abolish the ability of PSD-95 to enhance NMDAR surface and total expression (Fig. $4 b-e$ ). Similar results were observed with the NR2A antibody (data not shown). This finding indicates that the PDZ binding motif is critical to the effects of PSD-95 on NMDAR surface (and total) expression.

The finding that removal of the ESDV motif greatly reduces NMDA currents but does not alter receptor surface expression argues for a critical role for this motif in intrinsic channel properties and/or functional assembly. Because NR1-1a cannot insert efficiently in the cell surface in the absence of NR2 subunits (Okabe et al., 1999), it is likely that the inserted receptor subunits are heteromeric NR1/NR2 assemblies. A possible explanation is that removal of the ESDV motif results in insertion of a homogeneous population of channels with greatly reduced single channel conductance or $p_{0}$ (i.e., removal of the ESDV motif alters an intrinsic channel property). Alternatively, removal of the motif could result in insertion of a small number of correctly assembled, fully active channels and a large number of incorrectly assembled, essentially inactive channels.

\section{PSD-95 enhances the rate of insertion of new NMDA channels}

The results thus far indicate that PSD-95 enhances NMDAR surface expression in HEK-293 cells, but they do not distinguish between an increased rate of insertion and a reduced rate of internalization. To measure directly the effects of PSD-95 on NMDA channel insertion, we again used the quasi-irreversible NMDAR open-channel blocker, MK-801. Application of MK$801(5 \mu \mathrm{M})$ to HEK-293 cells expressing NMDARs in the absence or presence of PSD-95 blocked NMDA currents completely a
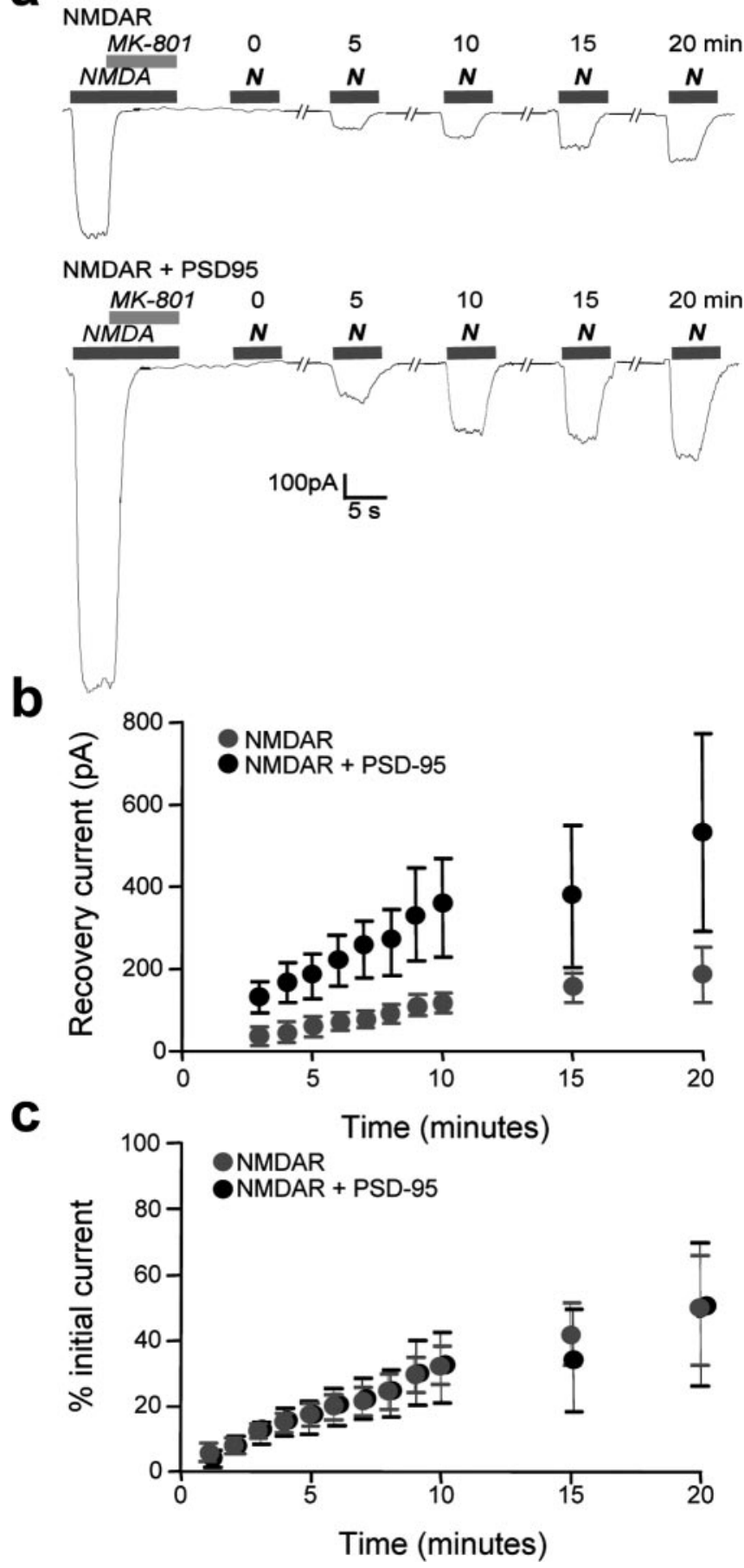

Figure 5. PSD-95 enhances the rate of insertion of new NMDA channels in the cell membrane. $a$, Representative traces showing NMDA-elicited currents in HEK-293 cells expressing NR1-1a/NR2A in the absence (top row) or presence (bottom row) of PSD-95. Application of MK-801 (5 $\mu \mathrm{M})$ in the presence of NMDA (1 mu with $50 \mu \mathrm{m}$ glycine) completely blocked the NMDA-elicited current within 1-2 sec (top and bottom rows, first record). After washout of NMDA and MK-801, test NMDA-elicited currents were recorded at the indicated times shown in minutes. $b, c$, Summary graphs of data in $a$. Gray circles indicate the absence of PSD-95; black circles indicate the presence of PSD-95. b, In HEK-293 cells expressing NMDARs in the presence of PSD-95, the rate of recovery of NMDA responses (indicated by the current amplitude of the recovered NMDA response as a function of time) was faster than in cells expressing receptors only ( $n=9$ for cells expressing NMDARs in the absence of PSD-95; $n=6$ for cells expressing NMDARs in the presence of PSD-95; $p<0.001$ for cells expressing PSD-95 vs cells expressing receptors only). $c$, Normalization of recovery responses shown in $b$ to the initial current. PSD-95 did not significantly alter the rate of insertion of new channels normalized to the initial current $(p>5)$. 


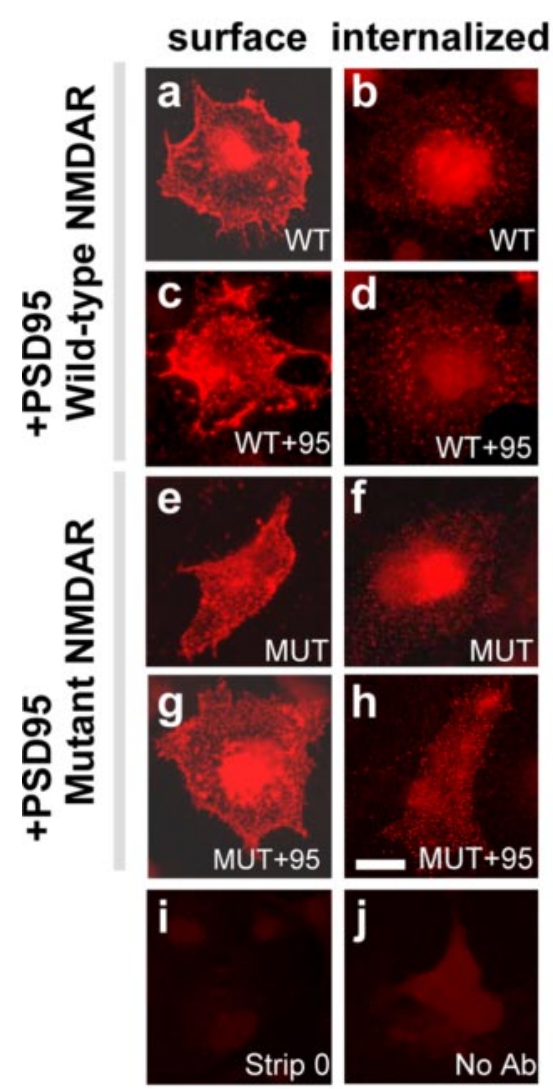

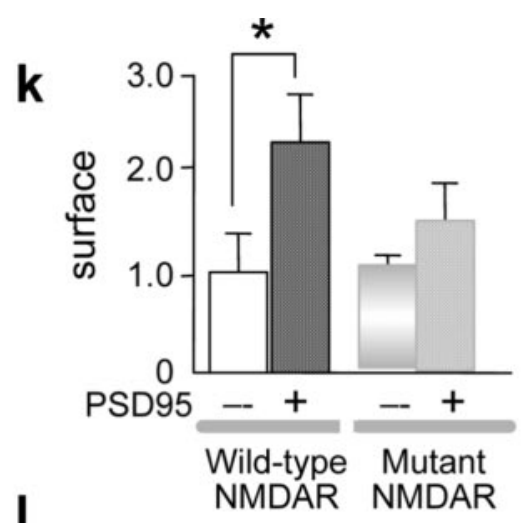
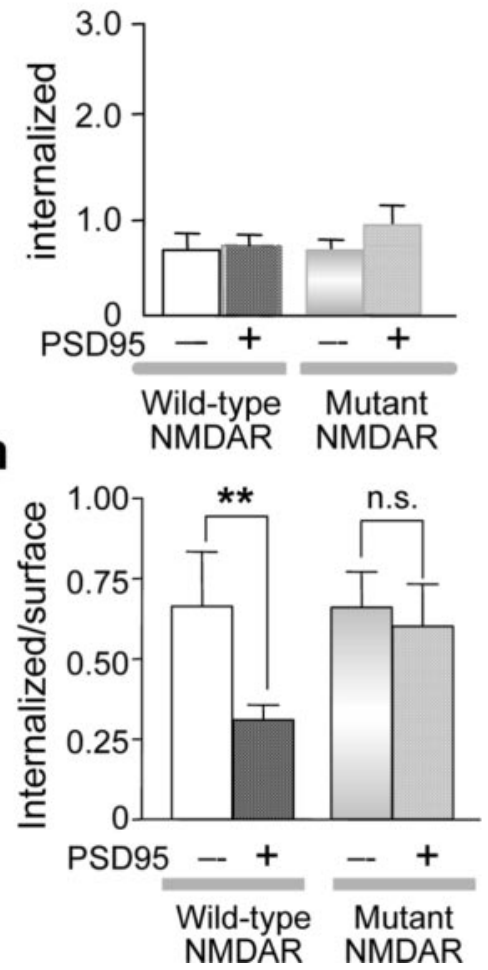

Figure 6. PSD-95 inhibits internalization of NMDARs. $a$, COS-7 cells were transiently transfected with wild-type YFP-NR1-1a/ NR2A $(a-d)$ or mutant YFP-NR1/NR2A $\Delta$ ESDV receptors $(e, f)$ in the absence $(a, b, e, f)$ or presence $(c, d, g, h)$ of myc-tagged PSD-95. Live cells were incubated with anti-YFP antibody at $4^{\circ} \mathrm{C}$ for $1 \mathrm{hr}$. To visualize surface receptors, cells were immediately fixed, permeabilized, and labeled with secondary antibody (left panels). To visualize internalized receptors, antibody-labeled cells were returned to the incubator and maintained at $37^{\circ} \mathrm{C}$ for $30 \mathrm{~min}(b, d, f, h)$; at the indicated times, cells were acid stripped to remove surface-bound antibody, fixed, permeabilized, and labeled with secondary antibody (right panels). PSD-95 increased the abundance of wild-type NMDARs receptors expressed at the cell surface (compare $a, c$ ) but did not significantly alter the abundance of NMDARs internalized at $30 \mathrm{~min}$ (compare $b, d$ ). PSD-95 did not detectably alter the surface expression (compare $e, g$ ) or abundance of internalized mutant NMDARs (compare $f, h$ ). $i, j$, Little or no immunolabeling was observed when antibody-labeled cells were acid stripped at $0 \mathrm{~min}$ ( $i$ ) or when primary antibody was omitted from the labeling reaction and cells were acid stripped at $30 \mathrm{~min}(j) . k-m$, Summary of experiments. In the case of wild-type NMDARs, PSD-95 increased the abundance of surface ( $k$, first and second bars) but not internalized receptors ( $I$, first and second bars); thus, the rate of receptor internalization was reduced ( $m$, first and second bars). In the case of mutant NMDARs, PSD-95 did not detectably alter the abundance of surface ( $k$, third and fourth bars) or internalized receptors ( $I$, third and fourth bars), nor did it affect the ratio of internalized to surface receptors ( $m$, third and fourth bars). Fluorescence intensity was quantitated by image analysis as described in Materials and Methods. Values are expressed as surface, internalized, or internalized/surface and represent the means \pm SEMs for five independent experiments, each performed in quadruplicate. ${ }^{* *} p<0.01$; Student's unpaired $t$ test.

within 1-2 sec (Fig. 5a, top and bottom rows, first record). After washout of MK-801 and NMDA, test NMDA applications ( $5 \mathrm{sec}$ ) were given at the indicated times shown in minutes to monitor the recovery of responses as a function of time. Because block by MK-801 is irreversible within the time frame of the experiment (Rosenmund et al., 1995), the rate of recovery of NMDA responses after block by MK- 801 is indicative of the rate of inser- tion of new channels at the cell surface. In the absence of PSD-95, the NMDA response recovered linearly for the first 10 min, after which recovery leveled off slightly; recovery to $\sim 200 \mathrm{pA}$ occurred by $20 \mathrm{~min}$ (Fig. $5 a$, top records). In HEK-293 cells expressing NMDARs in the presence of PSD-95, the rate of recovery of NMDA responses (indicated by the current amplitude of the recovered NMDA response) was faster (Fig. $5 a$, bottom records, $b$ ); however, the fractional recovery (indicated by the amplitude of the recovered current normalized to that of the initial current) was not altered significantly (Fig. $5 c$ ). These findings indicate that PSD-95 increases the rate of insertion of new NMDA channels and is consistent with a model whereby PSD-95 promotes forward trafficking of nascent receptors to the cell surface, where they are inserted via exocytosis (Standley et al., 2000; Sans et al., 2003).

\section{PSD-95 decreases the rate of NMDAR internalization}

To directly measure the effects of PSD-95 coexpression on receptor internalization, we coexpressed PSD-95 with wild-type N-terminally tagged YFP-NR1/NR2A receptors (Fig. $6 a-d$ ) and mutant YFP-NR1/ NR2A $\Delta$ ESDV receptors (Fig. $6 e-h$ ) in COS-7 cells and labeled surface receptors on live cells with an antibody directed to YFP. Cells were either fixed immediately and processed with secondary antibody to visualize surface receptors (Fig. 6, left panels) or returned to the incubator and maintained at $37^{\circ} \mathrm{C}$ for $30 \mathrm{~min}$ before acid stripping to remove external, surfacebound antibody. After incubation, cells were fixed, permeabilized, and processed with secondary antibody to visualize internalized receptors (Fig. 6, right panels). Coexpression of PSD-95 increased the cell surface expression of wild-type NMDARs (Fig. 6, compare $a, c$ ) with little effect on the number of internalized NMDARs (Fig. 6 , compare $b, d$ ), assessed at $30 \mathrm{~min}$ by immunofluorescence. Quantitation of the immunofluorescence indicated that PSD-95 increased the abundance of wildtype receptors at the cell surface by approximately twofold (Fig. $6 k$, first and second bars), with little or no effect on the abundance of internalized receptor (Fig. $6 l$, first and second bars). PSD-95 reduced the internalization rate defined as the fraction of wild-type NMDARs internalized per unit of time by $\sim 50 \%$ from $0.6634 \pm 0.1705$ for NMDARs only $(n=19)$ to $0.3095 \pm 0.0477$ for NMDARs plus PSD-95 $(n=20$; $p<0.05$ ) (Fig. $6 m$, first and second bars). The finding that PSD-95 decreases the ratio of internalized/surface receptors suggests that PSD-95 increases the residence time of NR1/NR2A 
receptors on the cell surface, at least in part, by reducing the fraction of surface receptors internalized per unit of time and is striking in that NR2A, which lacks any known consensus internalization motif, was internalized as rapidly as a Tac-NR2B construct, which contains the tyrosine-based internalization sequence YEKL (Roche et al., 2001). A prediction of our findings, now confirmed (Lavezzari et al., 2004), is the presence of a novel internalization sequence within the C-terminal domain of the NR2A subunit.

To examine whether the effects of PSD-95 on NMDAR internalization are caused by a direct binding interaction, we examined the effects of PSD-95 on internalization of the truncation mutant. In the absence of PSD-95, surface expression and the fraction of mutant NR1/NR2A $\Delta E S D V$ receptors internalized per unit of time were not significantly different from those of wildtype NMDARs. Thus, deletion of the PDZ binding motif failed to alter the stability of the receptors at the cell surface. In contrast to our finding with wild-type NMDARs, PSD-95 did not significantly alter internalization of the NR1/NR2A $\triangle E S D V$ truncation mutants (Fig. $6 m$, compare third and fourth bars). This finding provides evidence of the specificity of the action of PSD-95 on the stabilization of NMDARs at the cell surface. Some cells that were labeled for surface receptors, such as those illustrated in Figure 6, $a$ and $g$, showed clustered immunoreactivity in the center of the cell, presumably caused by coalescing of receptor puncta on the cell surface. To verify that the immunoreactivity was indeed authentic surface labeling and not caused by an artifact of fixation or handling of the sample resulting in breakdown of the plasma membrane, we performed two independent control experiments. We reasoned that if indeed the functional integrity of the plasma membrane were preserved, neither antibody nor tagged receptors on the cell surface would be internalized at time 0 . Little or no immunolabeling was observed when antibody-labeled cells were acid stripped at $0 \mathrm{~min}$, confirming the specificity of the labeling reaction for surface receptors (Fig. 6i), or when live cells were labeled in the absence of the primary antibody, confirming the specificity of the immunolabeling technique (Fig. 6j). A summary of the effects of PSD-95 on NMDAR properties is presented in Table 1.

\section{Discussion}

The network of scaffolding proteins at postsynaptic densities is crucial for synaptic plasticity in a wide variety of species. Here we show that PSD-95, a major constituent of the PSD and major binding partner of NMDARs at mature synapses, regulates NMDAR channel gating and trafficking (Table 1). Single-channel recording in outside-out patches excised from cells expressing NR1-1a/NR2A receptors revealed that potentiation of NMDAelicited currents by PSD-95 occurs via an increase in NMDA channel open probability, $p_{\mathrm{o}}$, times the number of channels, $n$, with little or no effect on unitary conductance, reversal potential, or mean open time of NMDA-activated channels. Studies involving the open-channel blocker MK-801 indicate that PSD-95 markedly increases channel opening rate, $k_{\beta}$, and number of functional NMDARs at the cell surface of HEK-293 cells. To our knowledge, our study represents the first example of regulation of NMDA channel gating by a scaffolding protein and major constituent of postsynaptic density. A simple scenario is that association of PSD-95 with NMDARs induces a conformational change in the receptor that directly alters the geometry of the NMDA channel pore. Alternatively, association of PSD-95 with NMDARs tethers the receptors in close proximity to a critical kinase that phosphorylates one or more receptor subunits and thereby affects channel gating. An important prediction of our findings is that scaffolding proteins such as PSD-95 would selectively increase the number of synaptic NMDARs and thereby selectively enhance NMDAR-mediated $\mathrm{Ca}^{2+}$ influx and activate downstream signaling cascades in spines. Consistent with this, disruption of the interaction between NMDARs and PSD-95 at cortical synapses dissociates synaptic NMDARs from downstream signaling molecules such as nNOS (Sattler et al., 1999).

The finding of an increased number of functional NMDARs is consistent with findings that coexpression of PSD-95 increases NMDA-elicited whole-cell currents in oocytes (Yamada et al., 1999; Iwamoto et al., 2004) and maximal number of [ $\left.{ }^{3} \mathrm{H}\right] \mathrm{MK} 801$ binding sites in HEK-293 cells (Rutter and Stephenson, 2000) (but see Losi et al., 2003). The finding that PSD-95 increases number of channels times open probability, $n p_{\mathrm{o}}$, and channel opening rate $k_{\beta}$, with little or no change in channel closing rate, $k_{\alpha}$, is consistent with findings of Losi et al. (2003) that PSD-95 does not alter the decay rate of the NMDA-mediated miniature EPSCs (mEPSCs). In that study, the changes in amplitude and kinetics of the NMDA mEPSC produced by PSD-95 overexpression were attributed to an exchange of NR2A for NR2B at cerebellar synapses rather than a direct effect of PSD-95 on gating properties. Our study extends those findings in that it shows direct regulation by PSD-95 of NMDA channel gating. Modification of channel function by a scaffolding protein such as PSD-95 has little precedent except in the case of voltage-sensitive potassium channels. PSD-95 significantly reduces single-channel conductance (with little or no effect on open probability) of Kv 2.3 channels (Nehring et al., 2000), but has little or no effect on Kv 1.4 macroscopic current amplitude or activation or inactivation kinetics (Jugloff et al., 2000).

\section{PSD-95 regulates NMDAR trafficking}

Our study also demonstrates the novel finding that PSD-95 regulates trafficking of intact, functional NMDARs. Cell-surface Western blots indicate that PSD-95 substantially increases the fraction of NMDARs at the cell surface and slightly increases total cell abundance of receptor subunits. Kinetic analyses suggest that PSD-95 increases the rate of insertion and decreases the rate of internalization of intact, functional receptors, accounting at least in part for the higher expression of channels at the cell surface and perhaps the total cell abundance of receptor subunits. Deletion of the PDZ binding motif in the $\mathrm{C}$ terminus of NR2A abolished the PSD-95-induced increase in surface expression and decrease in internalization, indicating specificity of PSD-95 action on NMDARs and a requirement for direct interaction of the binding partners. A possible mechanism is that PSD-95 enhances surface expression by stabilizing NMDARs on the cell surface and reducing the rate of receptor recycling and/or degradation. Alternatively, the increase in total NMDAR protein could be caused by increased synthesis of new receptor subunits.

Our finding that PSD-95 increases NMDAR total (cell) protein expression is consistent with observations of others that PSD-95 increases total cell expression of NMDARs in Xenopus oocytes (Yamada et al., 1999; Iwamoto et al., 2004) and HEK-293 cells, as assessed by Western blots (Rutter and Stephenson, 2000). Our findings that PSD-95 enhances insertion and suppresses internalization of NR1/NR2A receptors are consistent with observations that PSD-95 overexpression favors synaptic insertion of NR2A subunits (Losi et al., 2003) and suppresses internalization of $\beta_{1}$-adrenergic receptors (Hu et al., 2000) and Kv1.4 and Kir5.1 potassium channels (Jugloff et al., 2000; Tanemoto et al., 2002), and a chimeric Tac-NR2B construct (Roche et al., 2001). The 
present study extends those studies in that it shows that PSD-95 regulates trafficking of intact, functional NR1/NR2A receptors, which together with $\mathrm{NR} 1 / 2 \mathrm{~A} / 2 \mathrm{~B}$ triheteromers represent the major NMDAR subtypes present at mature synapses of the CNS (Tovar and Westbrook, 1999). Interestingly, the effect of PSD-95 on internalization of NMDARs containing NR2A (which lacks the consensus internalization motif YEKL) was as great as the effect on the Tac-NR2B construct (which contains the YEKL motif (Roche et al., 2001). A prediction of our findings [and now confirmed by Lavezzari et al. (2004)] is the presence of a novel internalization sequence within the $\mathrm{C}$-terminal domain of the NR2A subunit.

\section{Physiological significance}

Although a primary role of PDZ proteins may be to anchor and organize receptors at the synapse, considerable evidence implicates a chaperone role for PDZ proteins in the early events of assembly, processing, and delivery of receptor proteins. For example, the presence of a putative PDZ binding motif in the $\mathrm{C}^{\prime}$ cassette of NR1-3 splice variants overcomes (masks) an Arginine-Arginine-Arginine motif in the $\mathrm{C} 1$ cassette that serves as an endoplasmic reticulum (ER) retention signal and promotes forward trafficking of the receptors out of the ER (Standley et al., 2000; Scott et al., 2001; Xia et al., 2001). Thus, the two signals differentially regulate the surface expression of NR1 splice variants. A possible scenario in the present study is that PSD-95 acts as a chaperone protein to release vesicular-bound NR1 and promote forward trafficking of nascent receptors to the cell surface, where they are inserted via exocytosis; however, PSD-95 is unlikely to be a direct binding partner of NR1 and is more likely to serve as a partner for NR2A than for NR2B (Sans et al., 2003). Regulation of protein gating and trafficking by binding partners is likely to be a universal mechanism crucial for maintenance of the precise and highly ordered organization of the postsynaptic membrane. The present study shows that PSD-95 not only increases NMDAR insertion rate and stabilizes NMDARs at the cell surface, but also potentiates NMDA channel gating. Moreover, these findings suggest a novel mechanism for the activitydependent regulation of NMDAR-mediated responses. Synaptic activity modifies synaptic localization of PSD-95. Although prolonged activity at excitatory synapses enhances PSD-95 accumulation at synapses and reduces that of SAP102, blockade of synaptic activity has the opposite effect (Ehlers, 2003). Moreover, visual experience increases PSD-95 synaptic abundance, which in turn is critical to the control of developmental plasticity (Quinlan et al., 1999; Yoshii et al., 2003). Thus, PSD-95 could serve as a sensor that regulates NMDA function in response to alterations in synaptic activity. Changes in NMDAR number in the postsynaptic membrane provide a critical mechanism for rapidly altering synaptic strength (Carroll and Zukin, 2002). The physiological relevance of the PSD-95 effects is underscored by observations that targeted truncation and/or deletion of PSD-95 enhances LTP and severely impairs spatial learning (Migaud et al., 1998) and disrupts visual cortical plasticity (Fagiolini et al., 2003). Moreover, targeted deletion of PSD-93 reduces not only surface expression of NR2A and NR2B, but also the NMDA component of excitatory synaptic currents (Tao et al., 2003). Consistent with this, targeted deletion of the distal portion of the $\mathrm{C}$ terminus of NR2A (which contains the PDZ binding motif) greatly reduces synaptic NMDAR currents, with little or no effect on extrasynaptic NMDARs (Steigerwald et al., 2000). Given that PSD-95 and NMDARs are widely expressed throughout the CNS, regulation by PSD-95 of NMDA channel activity provides a potentially im- portant way to modulate the efficacy of synaptic transmission, LTP, and LTD and alter the LTP-LTD modification threshold.

\section{References}

Brenman JE, Chao DS, Gee SH, McGee AW, Craven SE, Santillano DR, Wu Z, Huang F, Xia H, Peters MF, Froehner SC, Bredt DS (1996) Interaction of nitric oxide synthase with the postsynaptic density protein PSD-95 and alpha1-syntrophin mediated by PDZ domains. Cell 84:757-767.

Carroll RC, Zukin RS (2002) NMDA-receptor trafficking and targeting: implications for synaptic transmission and plasticity. Trends Neurosci 25:571-577.

Carroll RC, Lissin DV, von Zastrow M, Nicoll RA, Malenka RC (1999) Rapid redistribution of glutamate receptors contributes to long-term depression in hippocampal cultures. Nat Neurosci 2:454-460.

Chen HJ, Rojas-Soto M, Oguni A, Kennedy MB (1998) A synaptic RasGTPase activating protein (p135 SynGAP) inhibited by CaM kinase II Neuron 20:895-904.

Chen N, Luo T, Raymond LA (1999) Subtype dependence of NMDA receptor channel open probability. J Neurosci 19:6844-6854

Constantine-Paton M, Cline HT (1998) LTP and activity-dependent synaptogenesis: the more alike they are, the more different they become. Curr Opin Neurobiol 8:139-148.

Craven SE, Bredt DS (1998) PDZ proteins organize synaptic signaling pathways. Cell 93:495-498.

Ehlers MD (2003) Activity level controls postsynaptic composition and signaling via the ubiquitin-proteasome system. Nat Neurosci 6:231-242.

El Husseini AE, Schnell E, Chetkovich DM, Nicoll RA, Bredt DS (2000) PSD-95 involvement in maturation of excitatory synapses. Science 290:1364-1368.

Fagiolini M, Katagiri H, Miyamoto H, Mori H, Grant SG, Mishina M, Hensch TK (2003) Separable features of visual cortical plasticity revealed by $N$-methyl-D-aspartate receptor 2A signaling. Proc Natl Acad Sci USA 100:2854-2859.

Garner CC, Nash J, Huganir RL (2000) PDZ domains in synapse assembly and signaling. Trends Cell Biol 10:274-280.

Hu LA, Tang Y, Miller WE, Cong M, Lau AG, Lefkowitz RJ, Hall RA (2000) beta 1-adrenergic receptor association with PSD-95. Inhibition of receptor internalization and facilitation of beta 1-adrenergic receptor interaction with N-methyl-D-aspartate receptors. J Biol Chem 275:38659-38666.

Irie M, Hata Y, Takeuchi M, Ichtchenko K, Toyoda A, Hirao K, Takai Y, Rosahl TW, Sudhof TC (1997) Binding of neuroligins to PSD-95. Science 277:1511-1515.

Iwamoto T, Yamada Y, Hori K, Watanabe Y, Sobue K, Inui M (2004) Differential modulation of NR1-NR2A and NR1-NR2B subtypes of NMDA receptor by PDZ domain-containing proteins. J Neurochem 89:100-108.

Jahr CE (1992) High probability opening of NMDA receptor channels by L-glutamate. Science 255:470-472.

Jugloff DG, Khanna R, Schlichter LC, Jones OT (2000) Internalization of the Kv1.4 potassium channel is suppressed by clustering interactions with PSD-95. J Biol Chem 275:1357-1364.

Kennedy MB (1997) The postsynaptic density at glutamatergic synapses. Trends Neurosci 20:264-268.

Kim E, Niethammer M, Rothschild A, Jan YN, Sheng M (1995) Clustering of Shaker-type $\mathrm{K}^{+}$channels by interaction with a family of membraneassociated guanylate kinases. Nature 378:85-88.

Kim E, Cho KO, Rothschild A, Sheng M (1996) Heteromultimerization and NMDA receptor-clustering activity of Chapsyn-110, a member of the PSD-95 family of proteins. Neuron 17:103-113.

Kim JH, Liao D, Lau LF, Huganir RL (1998) SynGAP: a synaptic RasGAP that associates with the PSD-95/SAP90 protein family. Neuron 20:683-691.

Kornau HC, Schenker LT, Kennedy MB, Seeburg PH (1995) Domain interaction between NMDA receptor subunits and the postsynaptic density protein PSD-95. Science 269:1737-1740.

Lan JY, Skeberdis VA, Jover T, Grooms SY, Lin Y, Araneda RC, Zheng X, Bennett MVL, Zukin RS (2001) Protein kinase C modulates NMDA receptor trafficking and gating. Nat Neurosci 4:382-390.

Lavezzari G, McCallum J, Dewey CM, Roche KW (2004) Subunit-specific regulation of NMDA receptor endocytosis. J Neurosci 24:6383-6391.

Li B, Otsu Y, Murphy TH, Raymond LA (2003) Developmental decrease in NMDA receptor desensitization associated with shift to synapse and interaction with postsynaptic density-95. J Neurosci 23:11244-11254. 
Losi G, Prybylowski K, Fu Z, Luo J, Wenthold RJ, Vicini S (2003) PSD-95 regulates NMDA receptors in developing cerebellar granule neurons of the rat. J Physiol (Lond) 548:21-29.

Malenka RC, Nicoll RA (1999) Long-term potentiation-a decade of progress? Science 285:1870-1874.

Migaud M, Charlesworth P, Dempster M, Webster LC, Watabe AM, Makhinson M, He Y, Ramsay MF, Morris RG, Morrison JH, O’Dell TJ, Grant SG (1998) Enhanced long-term potentiation and impaired learning in mice with mutant postsynaptic density-95 protein. Nature 396:433-439.

Nehring RB, Wischmeyer E, Doring F, Veh RW, Sheng M, Karschin A (2000) Neuronal inwardly rectifying $\mathrm{K}(+)$ channels differentially couple to PDZ proteins of the PSD-95/SAP90 family. J Neurosci 20:156-162.

Niethammer M, Kim E, Sheng M (1996) Interaction between the C terminus of NMDA receptor subunits and multiple members of the PSD-95 family of membrane-associated guanylate kinases. J Neurosci 16:2157-2163.

Okabe S, Miwa A, Okado H (1999) Alternative splicing of the C-terminal domain regulates cell surface expression of the NMDA receptor NR1 subunit. J Neurosci 19:7781-7792.

Ozawa S, Kamiya H, Tsuzuki K (1998) Glutamate receptors in the mammalian central nervous system. Prog Neurobiol 54:581-618.

Quinlan EM, Philpot BD, Huganir RL, Bear MF (1999) Rapid, experiencedependent expression of synaptic NMDA receptors in visual cortex in vivo. Nat Neurosci 2:352-357.

Roche KW, Standley S, McCallum J, Dune LC, Ehlers MD, Wenthold RJ (2001) Molecular determinants of NMDA receptor internalization. Nat Neurosci 4:794-802.

Rosenmund C, Feltz A, Westbrook GL (1995) Synaptic NMDA receptor channels have a low open probability. J Neurosci 15:2788-2795.

Rutter AR, Stephenson FA (2000) Coexpression of postsynaptic density-95 protein with NMDA receptors results in enhanced receptor expression together with a decreased sensitivity to L-glutamate. J Neurochem 75:2501-2510.

Rutter AR, Freeman FM, Stephenson FA (2002) Further characterization of the molecular interaction between PSD-95 and NMDA receptors: the effect of the NR1 splice variant and evidence for modulation of channel gating. J Neurochem 81:1298-1307.

Sans N, Prybylowski K, Petralia RS, Chang K, Wang YX, Racca C, Vicini S, Wenthold RJ (2003) NMDA receptor trafficking through an interaction between PDZ proteins and the exocyst complex. Nat Cell Biol 5:520-530.

Sattler R, Xiong Z, Lu WY, Hafner M, MacDonald JF, Tymianski M (1999) Specific coupling of NMDA receptor activation to nitric oxide neurotoxicity by PSD-95 protein. Science 284:1845-1848.
Scannevin RH, Huganir RL (2000) Postsynaptic organization and regulation of excitatory synapses. Nat Rev Neurosci 1:133-141.

Scott DB, Blanpied TA, Swanson GT, Zhang C, Ehlers MD (2001) An NMDA receptor ER retention signal regulated by phosphorylation and alternative splicing. J Neurosci 21:3063-3072.

Sheng M (2001) Molecular organization of the postsynaptic specialization. Proc Natl Acad Sci USA 98:7058-7061.

Standley S, Roche KW, McCallum J, Sans N, Wenthold RJ (2000) PDZ domain suppression of an ER retention signal in NMDA receptor NR1 splice variants. Neuron 28:887-898.

Steigerwald F, Schulz TW, Schenker LT, Kennedy MB, Seeburg PH, Kohr G (2000) C-terminal truncation of NR2A subunits impairs synaptic but not extrasynaptic localization of NMDA receptors. J Neurosci 20:4573-4581.

Tanemoto M, Fujita A, Higashi K, Kurachi Y (2002) PSD-95 mediates formation of a functional homomeric Kir5.1 channel in the brain. Neuron 34:387-397.

Tao YX, Rumbaugh G, Wang GD, Petralia RS, Zhao C, Kauer FW, Tao F, Zhuo M, Wenthold RJ, Raja SN, Huganir RL, Bredt DS, Johns RA (2003) Impaired NMDA receptor-mediated postsynaptic function and blunted NMDA receptor-dependent persistent pain in mice lacking postsynaptic density-93 protein. J Neurosci 23:6703-6712.

Tezuka T, Umemori H, Akiyama T, Nakanishi S, Yamamoto T (1999) PSD-95 promotes Fyn-mediated tyrosine phosphorylation of the $N$-methyl-D-aspartate receptor subunit NR2A. Proc Natl Acad Sci USA 96:435-440.

Tovar KR, Westbrook GL (1999) The incorporation of NMDA receptors with a distinct subunit composition at nascent hippocampal synapses in vitro. J Neurosci 19:4180-4188.

Xia H, Hornby ZD, Malenka RC (2001) An ER retention signal explains differences in surface expression of NMDA and AMPA receptor subunits. Neuropharmacology 41:714-723.

Yamada Y, Chochi Y, Takamiya K, Sobue K, Inui M (1999) Modulation of the channel activity of the epsilon2/zetal-subtype $N$-methyl-D-aspartate receptor by PSD-95. J Biol Chem 274:6647-6652.

Yoshii A, Sheng MH, Constantine-Paton M (2003) Eye opening induces a rapid dendritic localization of PSD-95 in central visual neurons. Proc Natl Acad Sci USA 100:1334-1339.

Zheng X, Zhang L, Wang AP, Bennett MVL, Zukin RS (1999) Protein kinase C potentiation of $N$-methyl-D-aspartate receptor activity is not mediated by phosphorylation of $N$-methyl-D-aspartate receptor subunits. Proc Natl Acad Sci USA 96:15262-15267. 